\title{
ARTIFICIAL NEURAL NETWORKS FOR INVESTIGATION OF THE MOST IMPORTANT FACTORS OF INDUSTRIAL TABLET MANUFACTURING ON THE DISSOLUTION OF ACTIVE PHARMACEUTICAL INGREDIENTS AS CRITICAL QUALITY ATTRIBUTES
}

\author{
MARCEL PRIKERŽNIK ${ }^{1,2 *}$, STANKO SRČIČ ${ }^{1}$ \\ ${ }^{1}$ University of Ljubljana, Faculty of Pharmacy, Department of Pharmaceutical Technology, 7 Aškerčeva Street, SI-1000 \\ Ljubljana, Slovenia \\ ${ }^{2}$ Lek Pharmaceuticals d. d., 57 Verovškova Street, SI-1000 Ljubljana, Slovenia
}

*corresponding author: marcel.prikerznik@novartis.com

Manuscript received: December 2020

\begin{abstract}
This research aimed to show the usefulness of artificial neural networks (ANNs) to investigate significant factors on the biopharmaceutical relevant parameter. It is the first time ANNs were used on such a comprehensive set of data collected during two-years of industrial production of tablets containing two active pharmaceutical ingredients (APIs). The feature selection technique was applied to the ANNs models to recognize critical material attributes and process parameters. Altogether, we have identified seven critical material attributes related to APIs, croscarmellose sodium, magnesium stearate, and colloidal silicon dioxide, together with five critical process parameters related to the roller compaction and tablet compression. The study demonstrates the usefulness of ANNs in facilitating a higher level of tablet manufacturing understanding.
\end{abstract}

\section{Rezumat}

Studiul a evaluat utilitatea rețelelor neuronale artificiale (ANN) cu scopul de a investiga factori ce influențează semnificativ parametri biofarmaceutici. Astfel, ANN-urile au fost aplicate pe un set cuprinzător de date colectate pe parcursul a doi ani de producție industrială a comprimatelor ce conțin două ingrediente farmaceutice active (API). Tehnica de selectare a caracteristicilor a fost aplicată modelelor ANN pentru a recunoaște atributele materiale critice și parametri procesului. În total, au fost identificate șapte atribute materiale critice legate de API, croscarmeloză sodică, stearat de magneziu şi dioxid de siliciu coloidal, împreună cu cinci parametri critici ai proceselor de compactare și comprimare. Studiul demonstrează utilitatea ANN-urilor în facilitarea înțelegerii procesului de obținere a comprimatelor.

Keywords: artificial neural networks, critical material attributes, critical process parameters, dissolution

\section{Introduction}

Tablet production is a complex process that slight variations of starting materials and manufacturing processes can dramatically affect the drug product quality. Therefore, it is crucial to identify all critical factors and understand interactions between critical material attributes, process parameters, and critical quality attributes $[12,16]$. The traditional trial-anderror approach requires many experiments to find an acceptable solution. As the number of factors increases, these experimental designs become highly inefficient, time-consuming, and expensive. On the other hand, observing the industrial level process provides a massive amount of data, but extracting crucial information is not always easy [7].

Artificial neural networks (ANNs) represent a promising modelling technique, especially for data sets having non-linear relationships encountered in pharmaceutical processes frequently. ANNs are biologically inspired computer programs designed to simulate how the human brain processes data. They detect relationships in data and learn through experience. One of the most straightforward and most often used ANNs algorithms is a multi-layer perceptron with backpropagation. The network consists of an input layer, an output layer, and one or more hidden layers of neurons (Figure 1).

The input layer neurons receive data from a data file, and output neurons provide response to the input data. Hidden neurons communicate only with other neurons. They are part of the inner structure that determines a solution to the problem. The behaviour of a neural network is influenced by the architecture itself, by the learning rule and by the transfer function that introduces non-linearity to the network. The use of ANNs in the pharmaceutical sciences ranges from interpretation of analytical data, design of drugs and dosage forms regarding biopharmaceutical data and clinical pharmacy $[2,10]$. 


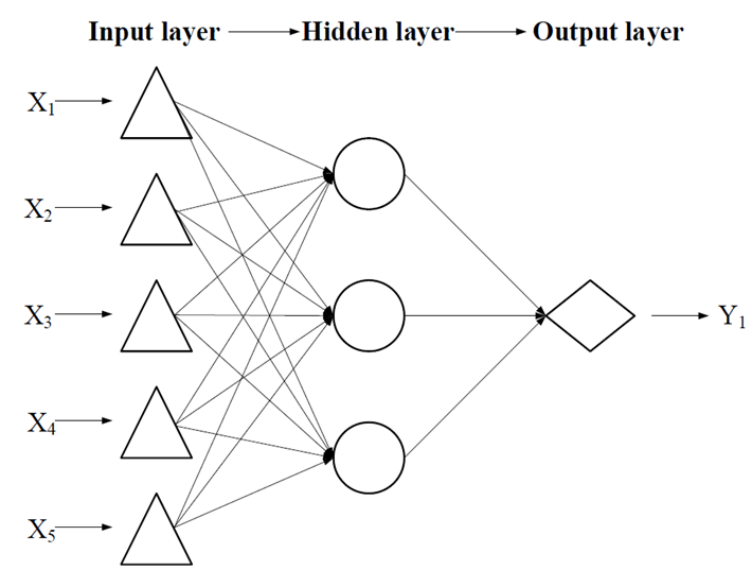

Figure 1.

Architecture of the neural network

ANNs based methods were successfully applied several times to investigate roller compaction and tablet compression processes $[5,11,17,19,25]$. However, only limited amounts of data were included in their models, excluding potentially important material attributes and process parameters. Moreover, only the physical properties of tablets, such as friability and disintegration time, were studied as targets, and only rarely quality attributes, such as drug dissolution [17]. Later parameter is biopharmaceutical relevant and affects bioavailability, efficacy and drug safety, thus being crucial from the patients' perspective [3].

The ranking of factors using the features selection was performed to identify all the essential material and processes parameters that affect the drug product quality in the given ANNs model. Feature selection is a technique for dimension reduction by removing irrelevant and redundant information from the data set. It is also a knowledge discovery tool for insight into the problems with the interpretation of the most important factors. Feature selection is enjoying increased attention due to the massive growth of data across many scientific disciplines [9].

An example of a feature selection method is algorithms from Relief family [23]. They are successful factor estimators and can correctly estimate their quality in problems with strong dependencies between factors in regression and classification. Basic idea of Relief algorithm is to assess the quality of factors according to how well their values distinguish between instances. For each instance, algorithm searches for its two nearest neighbours: one from the same class (nearest hit) and the other from the different class (nearest miss). Suppose randomly selected instance and nearest miss have different values of the factors. In that case, this factor separates two instances with different class values which are desirable, and the quality of this factor is increased. The process is repeated for all the instances. The adapted basic Relief algorithm for use in regression is called RReliefF algorithm. It is more robust and can deal with incomplete and noisy data. Based on the Relief algorithms, scores are assigned to all factors from -1 to 1 . More important factors get a higher positive score value. Irrelevant factors get values that are negative or close to 0 . More theory about Relief algorithms with examples can be found in the cited literature [21-23].

The primary goal of this paper was to thoroughly study and describe how all the possible factors of the starting material and production process (roller compaction and tablet compression) influence the drug dissolution of the immediate-release tablets containing two active pharmaceutical ingredients (APIs). Data were retrospectively collected from the industrially manufactured tablets over a two-year observation period to include as much variation as possible. Many different ANNs settings were tested to find an optimal solution. The most important material attributes and process parameters were identified and further discussed to reveal possible interactions between them and quality attributes. With these findings, we provide an improved process and product understanding that can result in assuring constant quality for an actual industrial pharmaceutical product.

\section{Materials and Methods}

\section{Materials}

Immediate-release tablets contained two APIs. 70\% of the formulation contained API 1, which was slightly soluble in water at $37^{\circ} \mathrm{C}$ and highly soluble according to the dose/solubility volume. Two sources of API 1 (both from Novartis, in Spain and Austria) were used. Both sources had the same specification limits and were used without preferences. API 2 (Novartis, Slovenia) presented around $11 \%$ of the formulation. It was freely soluble in water at $37^{\circ} \mathrm{C}$ and highly soluble according to the dose/solubility volume. API 2 was an extremely hygroscopic, moisture and temperature-sensitive material. The formulation contained additionally microcrystalline cellulose (Vivapur 102 SCG; Microcellulose Weissenborn GmbH \& Co., Germany), colloidal silicon dioxide (Aerosil 200; Pharma, Evonik Industries AG, Germany), crospovidone (Polyplasdone XL; ISP Chemicals LLC, USA), croscarmellose sodium (AcDiSol; DuPont Nutrition, Ireland; or Disolcel; Ming Tai Chemical Co., Ltd., Taiwan) and magnesium stearate (FACI Corporate S. p. A., Italy).

Manufacturing process

Tablets were produced on the industrial scale equipment with a batch size of granulate $287 \mathrm{~kg}$ in pharmaceutical company Lek d. d. (Prevalje, Slovenia). Due to the moisture sensitivity of API 2, the microcrystalline cellulose, croscarmellose sodium, and crospovidone were pre-dried using a high-shear vacuum dryer (Gral 600; Collette, Belgian). Both of the APIs, the microcrystalline cellulose, the colloidal silicon dioxide, half amount of the croscarmellose sodium, and half of the magnesium stearate were homogenized, and roller 
FARMACIA, 2021, Vol. 69, 4

compacted (K200/100; Bepex, Germany). The rest amount of the magnesium stearate and croscarmellose sodium and the whole quantity of the crospovidone were admixed to the homogenized granulate. Rotary tablet press (Kilian T300; Romaco, Germany) with oval, concave punches was used to compress granulate into tablets of $1.435 \mathrm{~g}$ in mass. Tablets were sampled throughout the whole batch and tested for dissolution.

\section{Dissolution}

According to the United States Pharmacopeia, apparatus 2 (VanKel Technology, USA) was used [27]. The test conditions were: 75 rotations per minute (rotary speed of the paddle) and $900 \mathrm{~mL}$ of water as the dissolution media at temperature $37 \pm 0.5^{\circ} \mathrm{C}$. After 30 minutes, $10 \mathrm{~mL}$ of sample was withdrawn and filtered through a cellulose nitrate membrane filter with a pore size of $0.8 \mu \mathrm{m}$. The first $5 \mathrm{~mL}$ of the filtrate was rejected, and the remaining part diluted 1:1 with dissolution media. The absorbance was determined spectrophotometrically at $220 \mathrm{~nm}$ (HPLC System, Waters, USA). If all of the six tested tablets passed the dissolution criteria, $\geq$ $90 \%$ for API 1 and $\geq 85 \%$ for API 2 , the dissolution was evaluated as S1 class dissolution. Otherwise, the dissolution was considered as a S2 class dissolution. This criterion is used for regular quality control testing. Data preparation

Data for the building of the model were selected retrospectively, covering two years of manufacturing 103 batches. Available material parameters from the internal or manufacturers' specifications for all seven input materials were included in the model. Further, parameters of the roller compaction and tablet compression processes were added to the model. Additionally, granulate hold time (time from final blending to beginning of compression phase), the yield of a compression phase, and in-process data from compression were included into the model building as well. Minimum tablet dissolutions per batch determined for API 1 and 2 were used as outputs of the models. The slowest tablet dissolution rate would have the most negative impact on the drug bioavailability and, consequently, on the treatment outcome and may not comply with the drug product characteristics.

Artificial neural networks modelling

Open-source software (Orange 3.18.0; Bioinformatics Lab, University of Ljubljana, Slovenia) using a multilayer perceptron algorithm with backpropagation was used to develop ANNs model [6]. The optimal combination of the transfer function, learning rule, and neural network architecture needed to be defined for the best model. It was done using a trial-and-error approach for minimum dissolution of API 1 and API 2, separately. Logistic sigmoid or hyperbolic tangents were used as a transfer function and optimizer in the quasi-Newton family (L-BFGS-B algorithm) or stochastic gradient descent were used as a learning rule for weight optimization in various models with 1 - 10 hidden layers containing 1 - 75 neurons when utilizing multiple models. Root Mean Square Error (RMSE) was used as a criterion to choose the best model settings. RMSE indicates the fit of the observations to the model: how accurate the drug dissolution is predicted. RMSE was obtained by 20 -folds crossvalidation sampling. The lower the RMSE, the better was the predictive power of the model.

Based on both best ANNs models, features selection was used to identify the most influential factors regarding the tablet dissolution for API 1 and for API 2. RReliefF algorithm [21] incorporated in the software was applied as feature selection, assigning quality estimates to factors and sorting them from the most to least influential. We chose and further interpreted the 10 highest-ranked factors for each API. Based on the available literature, this number of factors would suffice to describe the most significant factors affecting tablet dissolution [22].

Based on the dissolution classes ( $\mathrm{S} 1$ and $\mathrm{S} 2$ ), we compared if there is any statistically significant difference for these top ranked factors. Chi square test was used for categorical variables, two-sample t-tests for variables with normal distribution and nonparametric Mood's median tests for variables with non-normal distribution (Minitab 19.2020.3; LLC, Pennsylvania, USA).

\section{Results and Discussion}

After two years of production, the data from different sources (e.g., internal or manufacturer specifications, batch records, certificate of analysis) were collected into the final data set. All material attributes and most of the process parameters were presented completely for $100 \%$ of batches. The missing data (i.e., product temperature and compaction force during roller compaction for $23 \%$ of batches, auger speed and roller speed for $2 \%$ of batches, and all tablet compression parameters except compression speed $8 \%$ of batches), were handled by the software as unknown values. Among all 103 batches, unwanted delayed dissolution (S2 class) was attributed to 8 batches regarding API 1 dissolution and to 23 batches regarding API 2 dissolution.

To develop the best model with the lowest RMSE and, consequently, the highest accuracy, an optimal combination of the transfer function, learning rule, and neural network architecture needed to be found. This was done using a trial-and-error approach for minimum dissolution of API 1 and API 2, separately. Models, where logistic sigmoid as a transfer function was used, had RMSE based on cross-validation 1.821 $11.513 \%$ for dissolution of API 1, and $3.589-11.795 \%$ for dissolution of API 2. In comparison, if the hyperbolic tangents were used, RMSE was higher: 2.018 - 14.638\% and $4.342-11.799 \%$, for dissolution of API 1 and 2, respectively. L-BFGS-B algorithm as an optimizer returned RMSE of created models $1.821-3.334 \%$ 
FARMACIA, 2021, Vol. 69, 4

for dissolution of API 1, and 3.589-6.726\% for dissolution of API 2. Models with stochastic gradient descent achieved higher RMSEs: 2.018 - 14.638\% and $4.177-11.799 \%$, for dissolution of API 1 and API 2 , respectively. Based on that, a combination of the logistic sigmoid transfer function and L-BFGS-B optimizer were chosen for further modelling, as it showed preferable results for both APIs.

Next, better models were obtained, where only one hidden layer was used; RMSE was $1.821-2.547 \%$ for dissolution of API 1, and 3.589-6.180\% for dissolution of API 2. This was consistent with the theory that most functions can be approximated using a single hidden layer [18]. The final model for API 1 dissolution contained 10 neurons, and the model for API 2 dissolution contained 20 neurons, giving minimum RMSE $1.821 \%$ and $3.589 \%$, respectively. Coefficients of determination between actual and predicted minimum dissolution for the best two models were 0.75 for API 1 and 0.77 for API 2. The higher the coefficient, the better observations fit the model, and less scattered are points.

RReliefF algorithm assigned quality estimates to all factors (critical material attributes and process parameters). The scores were between 0.035 and 0.384 for API 1 dissolution, and between 0.046 and 0.368 for API 2 . The higher the score, the more important was factor for the model. 10 factors that most affected tablet dissolution of API 1 and API 2 are depicted separately in Table I and Table II, as this numbers sufficiently described all critical factors for this data size [22]. The minimum dissolution of both APIs as output factors was strongly correlated (89\%). The interaction and similar dissolution behaviour between both APIs were also showing in the most significant factors depicted by the RReliefF algorithm: eight factors were recognized as essential for the dissolution of both APIs. Altogether, 12 different significant factors were important for tablet dissolution of API 1 or API 2, or both. The next seven were related to the material attributes: the source of API 1, residual solvents of API 2, loss on drying and residue on the $0.071-\mathrm{mm}$ sieve during particle size determination of croscarmellose sodium, specific surface area and a bulk volume of magnesium stearate, and specific surface area of colloidal silicon dioxide. We identified five significant factors regarding process parameters: compaction force and product temperature during the roller compaction, and compression force and speed, along with force feeder speed during the tablet compression. Generally, the process factors were given a higher rank than factors related to the materials, meaning the process has a predominant impact on the tablet dissolution as a critical quality attribute.

Table I

Ten most significant factors impacting the dissolution of API 1 The ranking was made based on RReliefF algorithm applied on the final ANNs model for API 1. To each factor RReliefF score is assigned presenting quality estimate of this factor and $\mathrm{p}$ value based on the dissolution classes of API 1.

\begin{tabular}{|c|c|c|c|}
\hline Rank & Factor & RReliefF score & p value \\
\hline $\mathbf{1}$ & Main-pressure during tablet compression & 0.384 & 0.746 \\
\hline $\mathbf{2}$ & Compaction force during roller compaction & 0.369 & 0.420 \\
\hline $\mathbf{3}$ & Product temperature during roller compaction & 0.352 & 0.970 \\
\hline $\mathbf{4}$ & Source of API 1 & 0.349 & 0.224 \\
\hline $\mathbf{5}$ & Force feeder speed during tablet compression & 0.337 & 0.436 \\
\hline $\mathbf{6}$ & Residue on the 0.071-mm sieve during particle size determination of croscarmellose sodium & 0.334 & 0.004 \\
\hline $\mathbf{7}$ & The specific surface area of magnesium stearate & 0.314 & 0.388 \\
\hline $\mathbf{8}$ & Loss on drying of croscarmellose sodium & 0.305 & 0.000 \\
\hline $\mathbf{9}$ & Compression speed during tablet compression & 0.303 & 0.479 \\
\hline $\mathbf{1 0}$ & The specific surface area of colloidal silicon dioxide & 0.301 & 0.435 \\
\hline
\end{tabular}

Table II

Ten most significant factors impacting the dissolution of API 2 The ranking was made based on RReliefF algorithm applied on the final ANNs model for API 2. To each factor RReliefF score is assigned presenting quality estimate of this factor and $p$ value based on the dissolution classes of API 2.

\begin{tabular}{|c|c|c|c|}
\hline Rank & Factor & RReliefF score & p value \\
\hline $\mathbf{1}$ & Compaction force during roller compaction & 0.368 & 0.816 \\
\hline $\mathbf{2}$ & Main-pressure during tablet compression & 0.356 & 0.854 \\
\hline $\mathbf{3}$ & Force feeder speed during tablet compression & 0.355 & 0.023 \\
\hline $\mathbf{4}$ & Product temperature during roller compaction & 0.333 & 0.852 \\
\hline $\mathbf{5}$ & Residual solvents of API 2 & 0.332 & 0.038 \\
\hline $\mathbf{6}$ & Compression speed during tablet compression & 0.330 & 0.772 \\
\hline $\mathbf{7}$ & Residue on the 0.071-mm sieve during particle size determination of croscarmellose sodium & 0.324 & 0.000 \\
\hline $\mathbf{8}$ & Source of API 1 & 0.321 & 0.025 \\
\hline $\mathbf{9}$ & Bulk volume of magnesium stearate & 0.318 & 0.025 \\
\hline $\mathbf{1 0}$ & The specific surface area of magnesium stearate & 0.314 & 0.009 \\
\hline
\end{tabular}


We built groups based on the dissolution classes and compared if there is any statistically significant difference (Table I and II). Chi Square test was used for the categorical variable (API 1 source), two-sample t-tests were used for variables with normal distribution (compaction force during roller compaction, main pressure and force feeder speed during tablet compression), and nonparametric Mood's median tests for all other variables.

It is not straightforward to explore relations between significant factors and the dissolution of both APIs as output variables. It is due to the black-box nature of the ANNs and because these models lack a sound theoretical background [4]. ANNs also presuppose a non-linear relationship between variables. As certain relations were both linear and non-linear, effects of these variables were to some extent described also by linear relationships. This was mostly the case for the material attributes. The details for each significant factor are explained in the next sections.

Influence of material attributes

Two sources of API 1 were used. Although both sources of API 1 had the same specification limits, there was an influence of its source on the dissolution. Based on the ANNs models and RReliefF algorithms, the source of API 1 determines not only its own dissolution, but it is important also for the dissolution of API 2. However, there was a statistically significant difference of API 1 source when related to the dissolution classes of API 2 (Table II), but not for dissolution classes of API 1 (Table I). In practice, API 1 originated from Austria, was used in $15 \%$ of batches, and all of these batches passed S1 dissolution class for both APIs. Correlations between the Austrian source of API 1 and minimum dissolutions were 0.481 for API 1 and 0.522 for API 2. Other attributes of API 1 were not recognized as critical by ANNs models. In contrast, moderate correlation of API 1 source to some API 1 attributes was found: $\mathrm{pH}$ of $0.2 \%(\mathrm{w} / \mathrm{v})$ water solution ( -0.448 correlation to Austrian source), water content ( -0.403 correlation to Austrian source), and specific optical rotation (-0.414 correlation to Austrian source). Furthermore, a moderate correlation between the dissolution of API 2 and $\mathrm{pH}$ of $0.2 \%(\mathrm{w} / \mathrm{v})$ water solution of API 1 was perceived (-0.448). A weak correlation was observed between the dissolution of API 2 and other API 1 attributes (e.g., 0.241 for bulk density of API 1 and -0.144 for water content of API 1). It is assumed that API 1 might possess additional not identified property that was not included in the model, but could have some influence on drug disintegration, possibly affecting the bioavailability of both APIs.

Batches having higher API 2 organic residual solvents content showed better dissolution behaviour for API 2

(Figure 2). This attribute also had statistically significant differences when comparing both dissolution classes (Table II). The use of organic solvents during the synthesis of an API may be necessary for the yield or determine characteristics like a crystal form, purity and solubility [28]. As residual solvents cannot be removed entirely during the purification process, they should be present to the minimum extent possible as they can jeopardize the quality of the drug and the safety of the patients. On the other hand, they can enhance drug dissolution and positively affect the drug dissolution, as in this case. The content of residual solvents in the API 2 was between 0.22 and $0.48 \%$. The majority presented isopropanol, while acetone, ethyl acetate, and methanol altogether presented content lower than $0.05 \%$. The median for $\mathrm{S} 1$ dissolution class of API 2 was $0.33 \%$, and for S2 dissolution class, it was $0.36 \%$. Attribute had moderate correlations to next API 2 attributes: absorbance (0.579), $\mathrm{pH}$ of $0.2(\mathrm{w} / \mathrm{v})$ water solution (0.449), assay (-0.445) and tapped density (0.393). Correlations to other physical attributes were weaker: tapped density (0.393), particle size $\mathrm{d}_{50}(0.258)$ and particle size $\mathrm{d}_{90}$ (0.109).

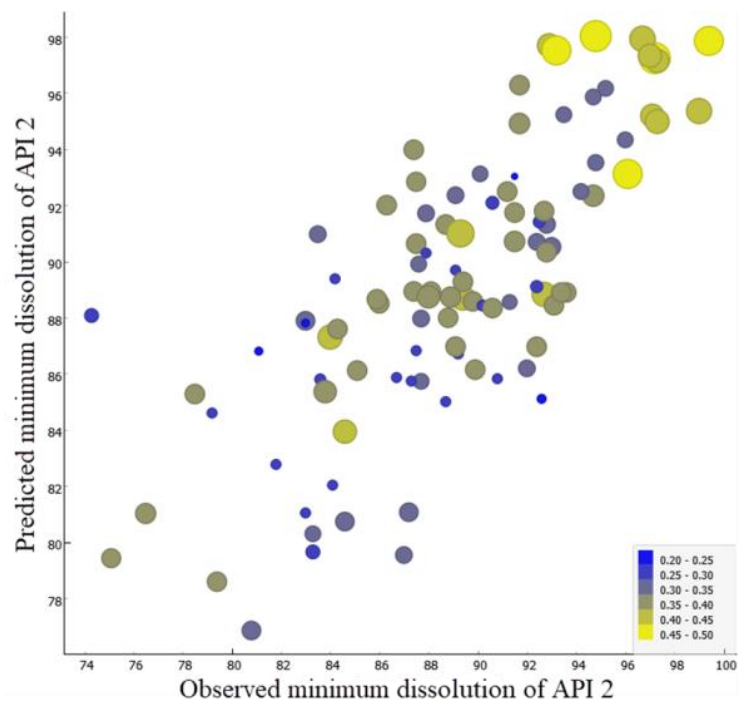

Figure 2.

Observed versus predicted plot for the minimum dissolution of API $2(\%)$

Batches are coloured and sized by the residual solvents content of API $2(\%)$

Croscarmellose sodium is a super disintegrant to ensure the quick onset of action in immediaterelease tablets. Croscarmellose sodium with greater particles swells more extensively [29, 30] and, in our case, showed improved dissolution for API 1 and API 2. Correlation of residue on the 0.071-mm sieve moderately correlated to the dissolution of API 1 (0.515) and API 2 (0.486). Differences were statistically significant to the dissolution classes (Table I and Table II). The particle size of croscarmellose was also practically relevant as all batches of croscarmellose having at least some residue on the $0.071-\mathrm{mm}$ sieve 
during particle size determination were attributed as the S1 dissolution class for both APIs. Loss on drying of croscarmellose sodium influenced drug dissolution and during the observed period was between $1.0 \%$ and $4.4 \%$. For the $\mathrm{S} 1$ dissolution class of API 1, loss on drying was, on average, $1.4 \%$ lower than for the S2 dissolution class for the same API, while the difference in both medians was even higher: $2.7 \%$. This difference was statistically significant (Table I), and correlation to the dissolution of API 1 was -0.601 . Lower moisture content might have been encouraged its hygroscopicity and additionally increased the dissolution of API 1.

Magnesium stearate is essential for lubrication in order to enhance the processability of blends. It is hydrophobic and can delay the dissolution [30]. The bulk volume of magnesium stearate had statistically significant effect on the dissolution of API 2 (Table II), correlation to the dissolution was -0.319 . Bulk volume for the observed period was between 50 and $56 \mathrm{~mL} / 10 \mathrm{~g}$ and was for the $\mathrm{S} 2$ dissolution class on average higher for $2 \mathrm{~mL} / 10 \mathrm{~g}$ than for $\mathrm{S} 1$ class, both for API 2. As well, differences in medians were the same: $2 \mathrm{~mL} / 10 \mathrm{~g}$. Additionally, dissolutions of both APIs were decreased due to the increased specific surface area of magnesium stearate. Correlation to the dissolution of API 1 was -0.568 and to the dissolution of API 2 was -0.551 . Statistically, this was significant only for dissolution classes of API 2 (Table II). Differences in specific surface area between $\mathrm{S} 1$ and $\mathrm{S} 2$ classes were on average $0.2 \mathrm{~m}^{2} / \mathrm{g}$ for the dissolution of API 1 and $0.3 \mathrm{~m}^{2} / \mathrm{g}$ for the dissolution of API 2 . Increased surface area leads to higher adhesion work with a strong hydrophobic layer of lubricant on the particle surface, which can result in reduced water penetration $[8,29]$. It makes specific surface area of magnesium stearate an essential parameter for dissolution behaviour and should be closely monitored. Bulk volume and specific surface area had only weak correlations to other attributes of magnesium stearate. The specific surface area of colloidal silicon dioxide did not show statistical significant influence to the dissolution class of API 1 (Table I). The practical relevance of colloidal silicon dioxide for tablet dissolution is lower in comparison to the both APIs, croscarmellose sodium and magnesium stearate, as only one attribute was depicted by the ANNs models and RReliefF algorithm, with the lowest score assigned. The specific surface area was on average higher for $5 \mathrm{~m}^{2} / \mathrm{g}$ at $\mathrm{S} 1$ dissolution class in comparison to $\mathrm{S} 2$ class, difference in both medians was $8 \mathrm{~m}^{2} / \mathrm{g}$. Utilized primarily as a glidant, it also has a positive influence on tablet disintegration [14].

Influence of process parameters

Roller compaction has positive effect on flowability of the powder blend, and might show an impact on dissolution [24]. Compaction force was based on the ANNs models and RReliefF algorithms the highest factor affecting the drug dissolution of API 2 and the second highest factor affecting the drug dissolution of API 1. The correlation of compaction force to dissolution was 0.244 for API 1 and 0.176 for API 2. The difference between both dissolution classes was $4 \mathrm{kN}$ for API 1 and $1 \mathrm{kN}$ for API 2. As the difference is statistically insignificant, it is essential to understand that only the optimum compaction force gives good quality of the granulate. At decreased compaction force ribbons are not formed, while over compaction breaks the ribbon, resulting in hardness, capping and friability problems during tablet compression [20].

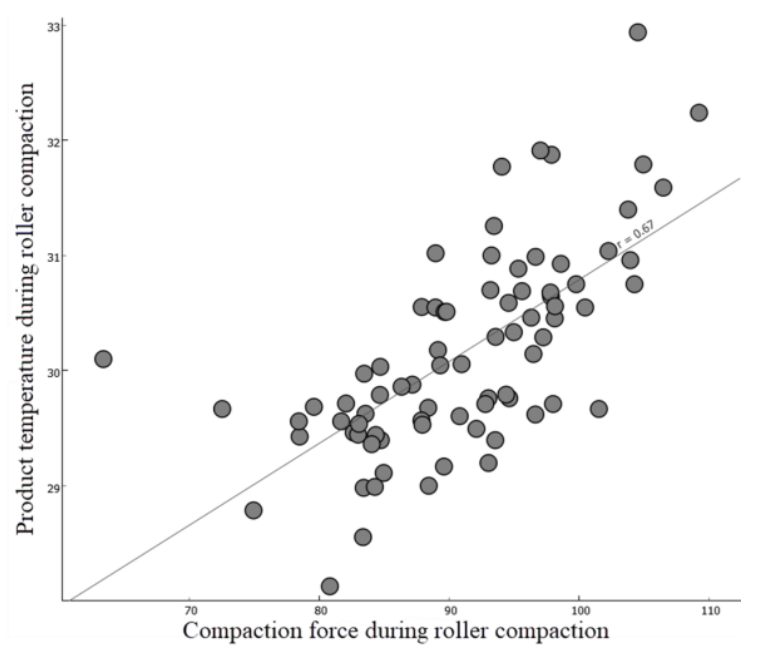

Figure 3.

Correlation between the compaction force $(\mathrm{kN})$ and product temperature $\left({ }^{\circ} \mathrm{C}\right)$

The coefficient of determination is shown as an r-value

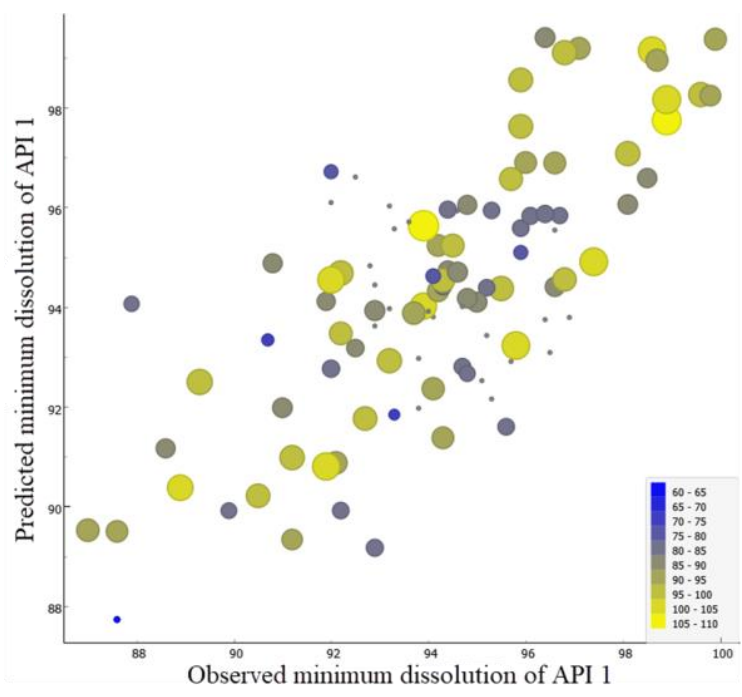

Figure 4.

Observed versus predicted plot for the minimum dissolution of API $1(\%)$

Batches are coloured and sized by the average compaction force $(\mathrm{kN})$ during roller compaction

Grey points in smaller size present batches with missing data for compaction force 


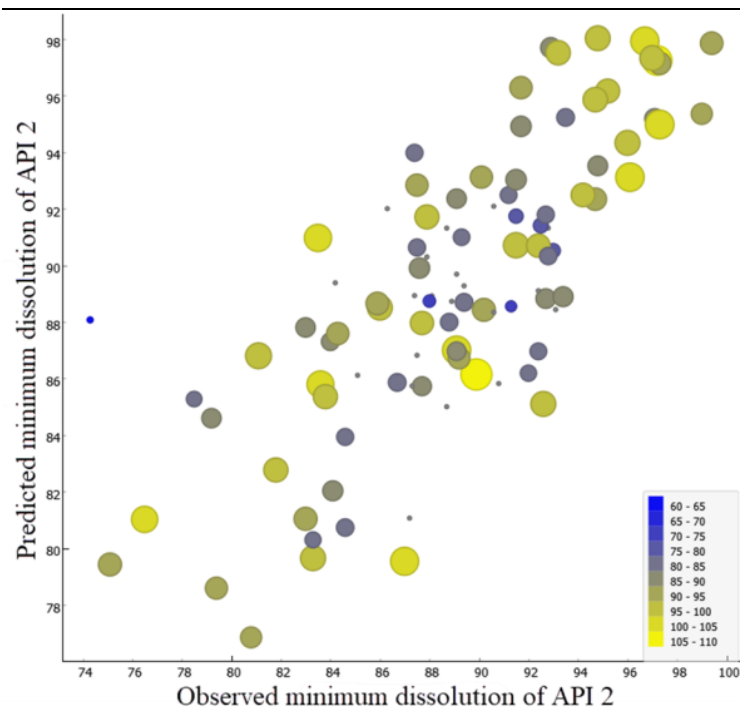

Figure 5.

Observed versus predicted plot for the minimum dissolution of API 2 (\%)

Batches are coloured and sized by the average compaction force $(\mathrm{kN})$ during roller compaction Grey points in smaller size present batches with missing data for compaction force

Higher compaction force also increases product temperature; the correlation between compaction force and product temperature can be observed in Figure 3. This can be one of the reasons why also product temperature is ranked relatively high among the factors. Having temperature-sensitive formulation, temperature control during roller compaction is an essential factor assuring acceptable drug quality. As seen from scatter plots in Figure 4 and Figure 5, relationships are mainly non-linear as it is not obvious to find correlations between compaction force and drug dissolution. Effects of compaction force and consequently, product temperature on drug dissolution were complex, possibly influenced by many other factors.

Tablet compression is the most crucial and challenging step during tablet production, as it depends not only on the starting material properties but also on the settings of many variables of the tablet press [15]. Main pressure was a parameter with the most decisive influence on API 1 dissolution and the second most important parameter affecting API 2. Generally, an increase in the main-pressure should decrease the release properties of tablets, but this is not always the case since tablet production results from complex interactions between incoming materials and process variables [1]. This is the reason why interactions were mainly non-linear and cannot be clearly described with linear methods (Figure 6).

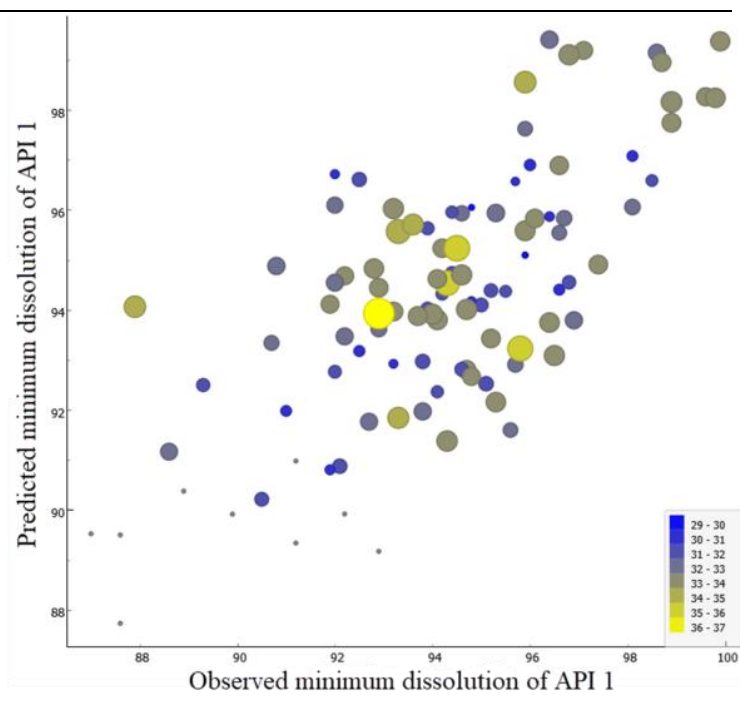

Figure 6.

Observed versus predicted plot for the minimum dissolution of API $1(\%)$

Batches are coloured and sized by the average mainpressure during tablet compression $(\mathrm{kN})$

Grey points in smaller size present batches with missing data for main-pressure

The second most important parameter during tablet compression that influenced drug dissolution of both APIs was force feeder speed. It was also the only process parameter with a statistically significant impact on drug dissolution classes of one of both APIs based on statistical tests (Table II). The difference in dissolution classes was on average 7 rotations/min for API 1 and 5 rotations/min for API 2. Higher force feeder speed would normally delay tablet dissolution in formulations with magnesium stearate due to over-lubrication of the compression blend [13]. Here, this was not very explicitly confirmed (Figure 7). A clear effect of a higher compression speed on delayed tablet dissolution can be observed in Figure 8. The mutual correlation of compression speed and force feeder speed is moderate: 0.459 . The correlation of compression speed to the dissolution of API 1 was -0.616 and to the dissolution of API 2 was -0.612. It shows and confirms that the consolidation kinetics of the granulate particles depends on the compression speed [26], which results in tablet structure and, consequently, in the change of tablet dissolution rate, i.e., the dissolution rate of API1 and API2.

Results showed that the production of desired quality pharmaceuticals is extraordinarily complex and composed of both non-linear and linear relationships. In our case, critical process parameters exhibited predominant effects over critical material attributes on drug dissolution. The reason is that ANNs models assume non-linearity, which was in our study more often observed for processes than for materials. 


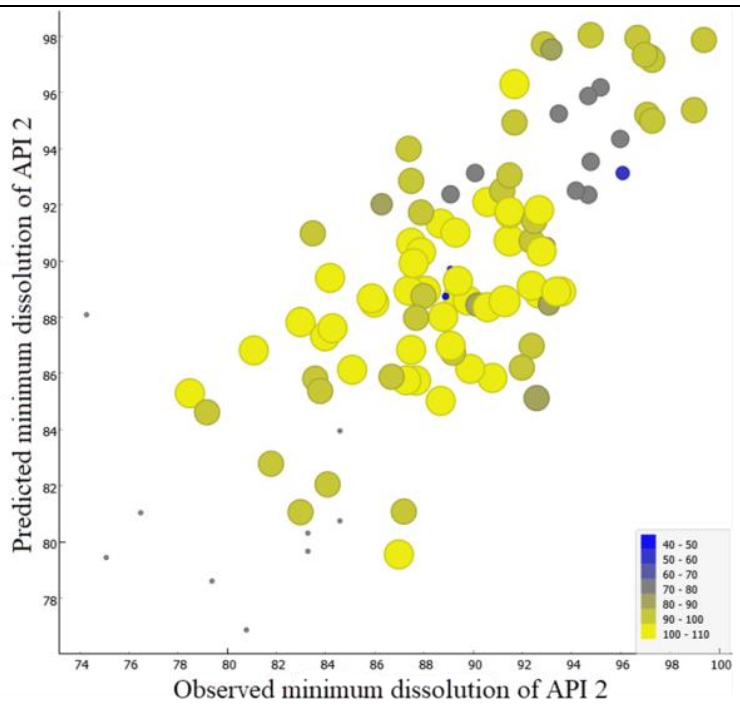

Figure 7.

Observed versus predicted plot for the minimum dissolution of API $2(\%)$

Batches are coloured and sized by the average force feeder speed (rotations per minute) during tablet compression

Grey points in smaller size present batches with missing data for force feeder speed

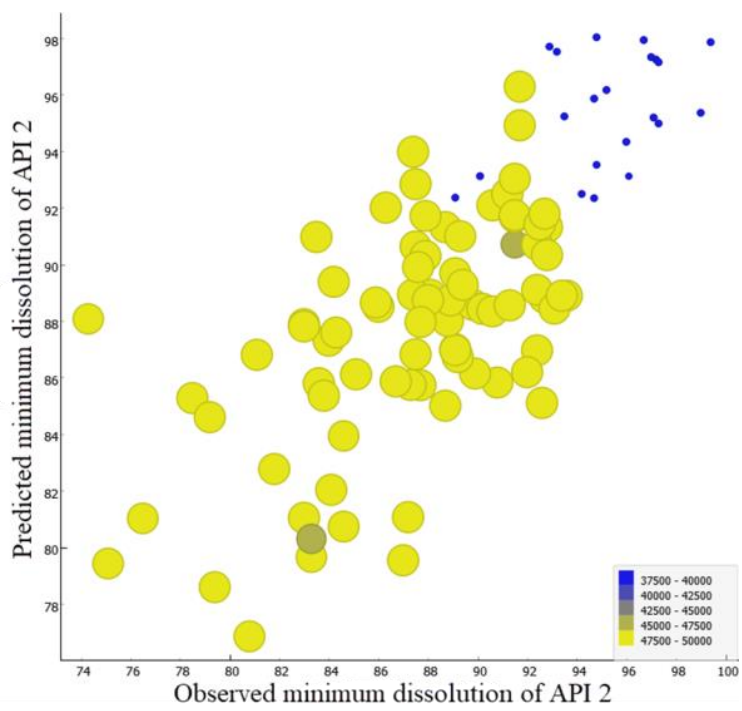

Figure 8.

Observed versus predicted plot for the minimum dissolution of API $2(\%)$

Batches are coloured and sized by the average compression speed (tablets per hour) during tablet compression

\section{Conclusions}

It has been demonstrated that ANNs, in connection with feature selection algorithm, can be applied to identify critical material attributes and critical process parameters of tablet manufacturing. The following critical factors were revealed and further discussed: source and residual solvents in APIs, loss on drying and particle size of croscarmellose sodium, specific surface area and a bulk volume of magnesium stearate, the specific surface area of colloidal silicon dioxide, compaction force, and compact temperature during roller compaction, and compression force, compression speed and force feeder speed during tablet compression. ANNs are especially useful for investigation of nonlinear relationships, which are common for pharmaceutical processes, but might not be detected with linear mathematical techniques. Apart from using classical linear methods, we suggest complementary, including non-linear methods, such as ANNs. It will facilitate a higher level of process and material understanding in the pharmaceutical industry and create opportunities for continuous improvements. Consequently, this leads to a more stable process, higher drug product quality and ultimately better patient care.

\section{Conflict of interest}

The authors declare no conflict of interest.

\section{References}

1. Adeleye OA, Relationship between compression pressure, mechanical strength and release properties of tablets. Polim Med., 2019; 49(1): 27-33.

2. Agatonovic-Kustrin S, Beresford R, Basic concepts of artificial neural network (ANN) modeling and its application in pharmaceutical research. J Pharm Biomed Anal., 2000; 22(5): 717-727.

3. Amidon GL, Lennernäs H, Shah VP, Crison JR, A theoretical basis for a biopharmaceutic drug classification: the correlation of in vitro drug product dissolution and in vivo bioavailability. Pharm Res., 1995; 12(3): 413420.

4. Barmpalexis P, Kanaze FI, Kachrimanis K, Georgarakis $\mathrm{E}$, Artificial neural networks in the optimization of a nimodipine controlled release tablet formulation. Eur J Pharm Biopharm., 2010; 74(2): 316-323.

5. Belič A, Škrjanc I, Zupančič Božič D, Karba R, Vrečer F, Minimisation of the capping tendency by tableting process optimisation with the application of artificial neural networks and fuzzy models. Eur J Pharm Biopharm., 2009; 73(1): 172-178.

6. Demšar J, Curk T, Erjavec A, Gorup C, Hočevar T, Milutinovič M, Možina M, Polajnar M, Toplak M, Starič A, Štajdohar M, Umek L, Žagar L, Žbontar J, Žitnik M, Zupan B, Orange: data mining toolbox in Python. J Mach Learn Res., 2013; 14: 2349-2353.

7. Ferreira AP, Tobyn M, Multivariate analysis in the pharmaceutical industry: enabling process understanding and improvement in the PAT and QbD era. Pharm Dev Techno., 2015; 20(5): 513-527.

8. Jójárt I, Sovány T, Pintye-Hódi K, Kása P, Study of the behaviour of magnesium stearate with different specific surface areas on the surface of particles during mixing. J Adhes Sci Techno., 2012; 26(24): 2737-2744.

9. $\mathrm{Li} \mathrm{Y,} \mathrm{Li} \mathrm{T,} \mathrm{Liu} \mathrm{H,} \mathrm{Recent} \mathrm{advances} \mathrm{in} \mathrm{feature} \mathrm{selection}$ and its applications. Knowl Inf Syst., 2017; 53: 551-557.

10. Madzarevic M, Medarevic D, Vulovic A, Sustersic T, Djuris J, Filipovic N, Ibric S, Optimization and prediction of ibuprofen release from 3D DLP printlets 
using artificial neural networks. Pharmaceutics, 2019; 11(10): 544: 1-16.

11. Mansa RF, Bridson RH, Greenwood RW, Barker H, Seville JPK, Using intelligent software to predict the effects of formulation and processing parameters on roller compaction. Powder Technol., 2008; 181(2): 217-225.

12. Mishra V, Thakur S, Patil A, Shukla A, Quality by design $(\mathrm{QbD})$ approaches in current pharmaceutical set-up. Expert Opin Drug Deliv., 2018; 15(8): 737-758.

13. Narang AS, Rao VM, Guo H, Lu J, Desai DS, Effect of force feeder on tablet strength during compression. Int J Pharm., 2010; 401(1-2): 7-15.

14. Owen S, Colloidal Silicon Dioxide. In Rowe R, Sheskey P, Owen S, Handbook of pharmaceutical excipients, Pharmaceutical Press and American Pharmacists Association, London (UK), 2006: 188-191.

15. Patel S, Kaushal AM, Bansal AK, Compression physics in the formulation development of tablets. Crit Rev Ther Drug Carrier Syst., 2006; 23(1): 1-65.

16. Pharmaceutical Development Q8(R2). 2009; https:// database.ich.org/sites/default/ Q8_R2_Guideline.pdf.

17. Pishnamazi M, Ismail HY, Shirazian S, Iqbal J, Walker GM, Collins MN, Application of lignin in controlled release: development of predictive model based on artificial neural network for API release. Cellulose, 2019; 26: 6165-6178.

18. Ripley BD, Pattern recognition and neural networks. UK: Cambridge University Press, Cambridge, 1996.

19. Rocksloh K, Rapp FR, Abu Abed S, Muller W, Reher M, Gauglitz G, Schmidt PC, Optimization of crushing strength and disintegration time of a highdose plant extract tablet by neural networks. Drug Dev Ind Pharm., 1999; 25(9): 1015-1025.

20. Srikant P, Akash J, Makesh D, Astik S, Roller compaction design and critical parameters in drug formulation and development: Review. Int J Pharmtech Res., 2015; 7(1): 90-98.
21. Šikonja Robnik M, Kononenko I, An adaptation of Relief for attribute estimation in regression. Mach Learn.: Proceedings of the Fourteenth International Conference on Machine Learning, 1997; 296-304.

22. Šikonja Robnik M, Kononenko I, Comprehensible interpretation of Relief's estimates. Mach Learn.: Proceedings of the Eighteenth International Conference on Machine Learning, 2001; 433-440.

23. Šikonja Robnik M, Kononenko I, Theoretical and empirical analysis of ReliefF and RReliefF. Mach Learn., 2003; 53(1-2): 23-69.

24. Teng Y, Qiu Z, Wen H, Systematical approach of formulation and process development using roller compaction. Eur J Pharm Biopharm., 2009; 73(2): 219-229.

25. Turkoglu M, Aydin I, Murray M, Sakr A, Modeling of roller-compcation process using neural networks and genetic algorithms. Eur J Pharm Biopharm., 1999; 48: 239-245.

26. Tye CK, Sun CC, Amidon GE, Evaluation of the effects of tableting speed on the relationships between compaction pressure, tablet tensile strength, and tablet solid fraction. J Pharm Sci., 2005; 94(3): 465-472.

27. United States Pharmacopeial Convention, United States Pharmacopoeia (USP): 711 Dissolution. 2019.

28. United States Pharmacopoeial Convention, United States Pharmacopoeia (USP): 467 Residual solvents. 2019.

29. Zarmpi P, Flanagan T, Meehan E, Mann J, Fotaki N, Biopharmaceutical aspects and implications of excipient variability in drug product performance. Eur J Pharm Biopharm., 2017; 111: 1-15.

30. Zhao N, Augsburger LL, The influence of product brandto-brand variability on superdisintegrant performance. A case study with croscarmellose sodium. Pharm Dev Technol., 2006; 11(2): 179-185. 